\title{
Effect of Maternal Pethidine on Breast Feeding Behavior of Infants in Cesarean Section by Spinal Anesthesia: A Randomized Controlled Trial
}

\author{
Majid Dejbakht, MSc ; Zohreh Montaseri, MSc²; Jalal Saem, MD³; Mehrdad Rezaei, MD; Marzieh Akbarzadeh, MSc ${ }^{5 *}$ \\ ${ }^{1}$ Department of Nursing, Gerash Amir-al-Momenin Medical and Educational Center, Gerash University of Medical Sciences, Gerash, \\ Iran \\ ${ }^{2}$ Community Based Psychiatric Care Research Center, Department of Nursing, School of Nursing and Midwifery, Shiraz University \\ of Medical Sciences, Shiraz, Iran \\ ${ }^{3}$ Department of Anesthesiologist and Intensive Care, Shiraz University of Medical Sciences, Shiraz, Iran \\ ${ }^{4}$ Department of Pediatrics, Research Center of Neonatology, Shiraz University of Medical Sciences, Shiraz, IR Iran \\ ${ }^{5}$ Maternal-Fetal Medicine Research Center, Department of Midwifery, School of Nursing and Midwifery, Shiraz University of Medical \\ Sciences, Shiraz, IR Iran
}

\begin{abstract}
Background: Pain control methods after cesarean section may interfere with infant breast-feeding. The aim of this study was to evaluate the effect of pethidine on breast feeding of infants born via cesarean section with spinal anesthesia.

Methods: In this randomized double-blind clinical trial, we evaluated 116 infants born via cesarean section in Gerash Amiralmomenin hospital (Southern Iran) in 2017. The subjects were selected through purposive sampling and randomly by permuted block randomization and assigned to intervention and control groups. The test group received $100 \mathrm{mg}$ of pethidine as intravenous infusion and the control group received only routine cares. Infants' breast feeding behavior in both groups was recorded within 48 hours of hospitalization, using the standard tool for rapid assessment of infant feeding behavior, which consists of 4 main components of breastfeeding, including readiness to feed, rooting, latching, and sucking with a score range of 0 to 3 for each component evaluated at 1, 6, 12, 24, 36, and 48 hours postnatally. Data were analyzed using independent $t$ tests and chi-square test.

Results: The highest score of breast-feeding behavior pertained to sucking reflexes in the control group and the lowest score to breast feeding readiness in the pethidine group. Readiness for feeding in the control group $(2.09 \pm 0.53)$ was significantly higher than the pethidine group $(1.81 \pm 0.61)(95 \% \mathrm{Cl}: 0.0552,0.5092$ and $P=0.015)$. Sucking reflex $(95 \% \mathrm{Cl}:-0.1461,0.2208$ and $P=0.687)$, latching $(95 \% \mathrm{Cl}:-0.3012,0.0345$ and $P=0.118)$ and rooting reflexes (95\% $\mathrm{Cl}:-0.1685,0.2342$ and $P=0.747)$ were almost equal in the control group $(2.54 \pm 0.49,2.52 \pm 0.38,2.5 \pm 0.48$, respectively) and pethidine groups $(2.51 \pm 0.43$, $2.65 \pm 0.45,2.46 \pm 0.53$, respectively). The total score of feeding behavior in the control group $(9.66 \pm 1.04)$ was higher than that of the pethidine group $(9.44 \pm .69)(95 \% \mathrm{Cl}:-0.2032,0.6412$ and $P=0.306)$. There was no significant difference between the infants' feeding frequency (95\% Cl: $-0.269,1.930$ and $P=0.137)$ and duration of feeding $(95 \% \mathrm{Cl}:-3.2067,0.4597$ and $P=0.14)$.

Conclusion: Evaluation of infants in the first 48 hours after birth showed that those babies whose mothers received pethidine were less willing to start breast-feeding. However, other components of breast-feeding behaviors were similar.

Keywords: Breast feeding, Behavior, Cesarean section, Pethidine, Spinal

Cite this article as: Dejbakhat M, Montaseri Z, Saem J, Rezaei M, Akbarzadeh M. Effect of Maternal Pethidine on Breast Feeding Behavior of Infants in Cesarean Section by Spinal Anesthesia: A Randomized Controlled Trial. Arch Iran Med. 2021;24(8):591-598. doi: 10.34172/aim.2021.84
\end{abstract}

Received: April 4, 2020, Accepted: : September 30, 2020, ePublished: August 1, 2021

\section{Introduction}

Cesarean section was initially performed for saving the lives of mothers who were at risk of death due to problems with vaginal delivery. In recent years, a growing trend has been observed for cesarean sections. ${ }^{1}$ The acceptable cesarean rate determined by the World Health Organization (WHO) is $15 \%$ for better maternal and fetal outcomes. ${ }^{2}$ The rate of cesarean delivery in developed and non-developed countries is expanding. ${ }^{3}$ Some countries such as England and the US have had a progressive increase in the cesarean delivery, ${ }^{4,5}$ while some have been successful in controlling cesarean delivery. ${ }^{6}$ In recent years, the rate of cesarean sections has been growing in some Middle Eastern countries, including Iran. ${ }^{7}$

The use of different methods of induced analgesia or anesthesia is an integral part of cesarean delivery, and the choice of a low-risk, desirable and affordable method for both mother and infant is very important. ${ }^{8}$ The doctor's decision about choosing the type of general or regional anesthesia to induce analgesia for cesarean section primarily depends on the clinical conditions of the mother and fetus, as well as the degree of emergency. ${ }^{9}$ 
In the cesarean section, two methods of general anesthesia and regional anesthesia are used. General anesthesia is preferable in case of fetal distress or emergency cesarean section (for patients with some problems such as hypotension, preeclampsia and mental imbalance). Regional anesthesia (epidural, spinal) is most commonly used for non-emergency cesarean sections and in healthy women if they need to stay awake). Regional anesthesia minimizes the risk of maternal pulmonary aspiration, and embryo depression speeds up the nutrition and lactation of the infant and improves the recovery periods of the mother. In general, due to the risks of general anesthesia, the use of regional anesthesia is widespread in developing countries. ${ }^{10}$

Today, spinal anesthesia is the most commonly used method for non-emergency cesarean delivery, ${ }^{11}$ and it allows the mother to immediately interact with her infant after cesarean section. ${ }^{12}$ In a study in the United States and England, it was shown that $95 \%$ of cesarean sections were performed by spinal anesthesia. ${ }^{9}$ Also, studies in Iran indicate a high rate of spinal anesthesia in cesarean sections. In a study in Iran, 54\% of cesarean sections were performed by general anesthesia and $46 \%$ by spinal anesthesia. $^{13}$

One of the challenges of cesarean surgery is the management and control of pain in the mother. Pethidine is one of the most commonly used drugs throughout the world and is now widely used in obstetrics and gynecological surgeries because it is cheap, has a short effect at the onset time, and is easy to start and administer. ${ }^{14}$

An important concern about the administration of pethidine is its potential effects on the infant. Various studies have shown that pethidine administration to the mother can be harmful for the infant ${ }^{15}$ and it affects the infant's feeding behavior (readiness to feed, rooting, latching and sucking). ${ }^{16}$

In a study conducted by Arvidsson in Sweden, the feeding behaviors of 28 infants were examined and it was found that infants whose mothers had received analgesia were less successful in rooting and breastfeeding compared to other infants. ${ }^{17}$

A study by Nissen et al study investigated the administration of pethidine in different stages of vaginal delivery on the feeding behavior of their infants. They concluded that intramuscular administration of $100 \mathrm{mg}$ of pethidine for analgesia during labor can adversely affect the infants' breast feeding. It seems that infants are sensitive even to low doses of narcotic analgesics. ${ }^{18}$

In this regard, further research is required to be conducted on the safety of pethidine administration to the mother after cesarean section, the secretion of this drug and its metabolites in breast milk, and the potential impact that this drug can have on the infants' breastfeeding behavior. On the other hand, studies conducted on the effect of administering pethidine on the infants' feeding behavior are limited. In addition, genetic differences in different societies can affect the metabolism of pethidine, its level of transmission to the infant, and the occurrence of unwanted effects. In our country, the studies conducted so far have examined the effects of pethidine during normal delivery on the weight gain of the infant, the frequency of breastfeeding, and the choice of feeding (breast milk or formula feeding). Therefore, it seems that other potential side effects of pethidine should also be considered. In this study, we aimed to investigate the effect of pethidine on the feeding behavior of infants born to cesarean section by the spinal method.

\section{Patients and Methods}

The present study is a randomized double-blind clinical trial. The study population included all infants whose mothers were referred to the hospital for non-emergency delivery in 2017.

The study subjects were selected through purposive sampling among the mothers who referred to the Gerash Amiralmomenin hospital (southern Iran) for nonemergency cesarean section by the spinal method. They were randomly assigned to the intervention and control groups. After sample size calculation, permuted block randomization was used to assign patients to the two groups in a 1:1 ratio. Then, approximately 19 blocks of 6 were prepared and the patients were consecutively assigned to the blocks until the sample size for each group was completed. The responsible anesthesiologist was aware of patients' group. However, the patients and the investigators collecting the data were unaware of the treatment assignment (double-blinded). They were also reassured that they could withdraw from the study whenever they desired.

The sample size was determined after statistical counseling and according to objectives and type of the study by using Pass 11 software, considering a type-one error of $5 \%$ and power of $90 \%$, and based on the article entitled "A comparison of early sucking dynamics during breastfeeding after cesarean section and vaginal birth.${ }^{19}$ The mean (SD) was $11.2(0.7)$ in the control group and 10.5 (1.4) in the test group. The sample size in each group was determined at 53 individuals by considering a drop rate of $9 \%$. Finally, in each group, a sample size of least 58 individuals was calculated.

A total of 116 individuals were studied. During the study in the control group, four cases were excluded due to the infant's simultaneous consumption of formula milk, two cases due to the separation of the mother from the infant, and three cases due to lack of cooperation. In the pethidine group, two cases were excluded due to the mother's pain and the need for repetition of the pethidine dose and four cases due to simultaneous consumption of formula milk and breast milk. Finally, 49 cases in the control group and 52 cases in the pethidine group were analyzed (Figure 1).

The study inclusion criteria were age 18-36 years, singleton, non-emergency cesarean section with gestational age between 38 and 42 weeks, mother's willingness to breastfeed, ASA (American Society of 


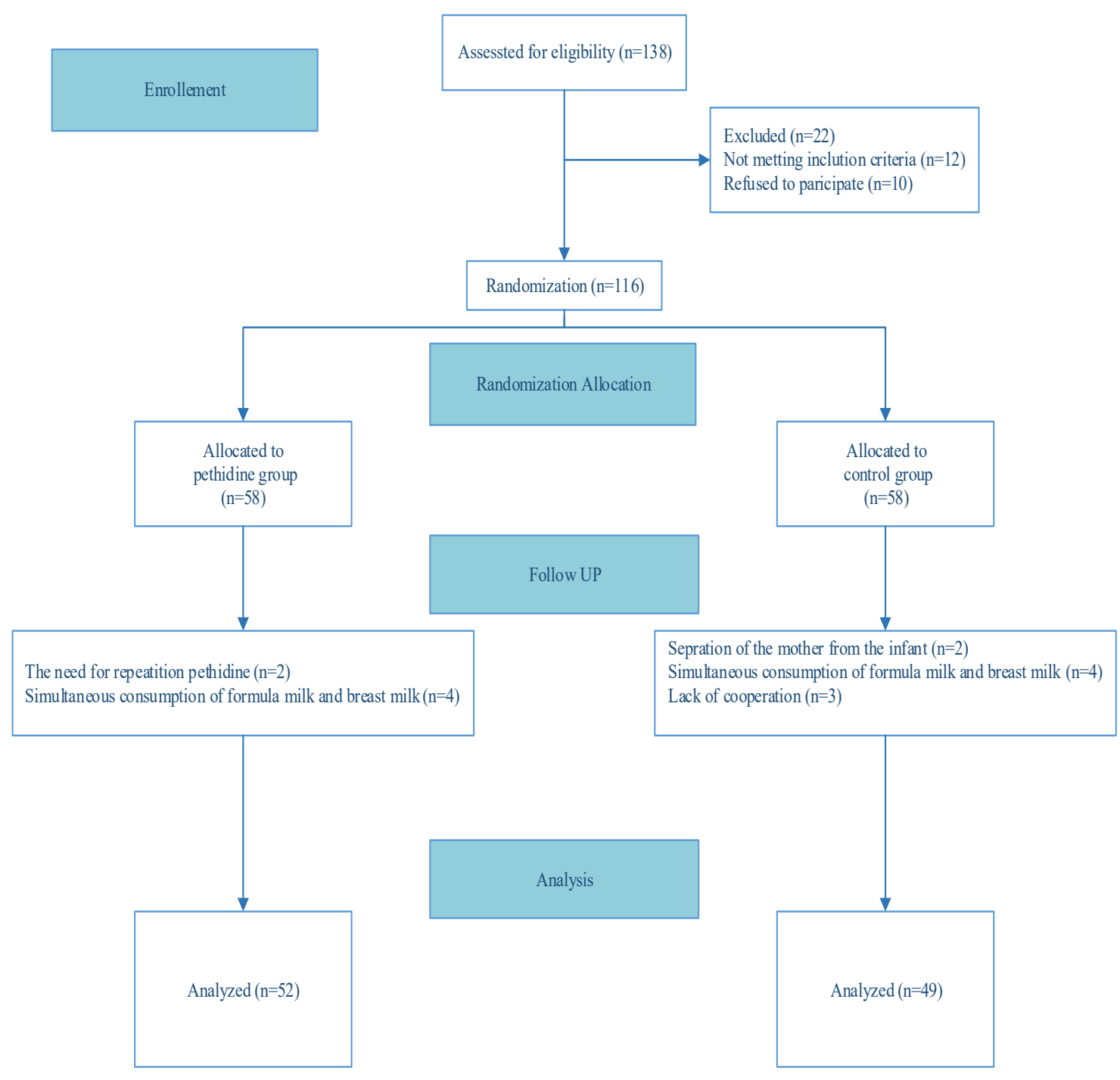

Figure 1. CONSORT Flow Diagram of Sampling.

Anesthesiologists) class I, willingness to participate in the study, and no history of mother's mental illness and depression.

The study exclusion criteria were infant weight less than $2500 \mathrm{~g}$ and more than $4000 \mathrm{~g}$, first or fifth minute Apgar scores below seven, meconium-stained amniotic fluid, any abnormalities in the infant, using drugs that are contraindicated during breastfeeding by mothers, need to repeat the dose of pethidine, separation of the mother from the baby, infant feeding with formula milk, and lack of mother's willingness to continue the study.

The tools used in this study consisted of four sections as follows. Section 1: Mothers' demographic and pregnancy information including age, weight, gestational age, number of pregnancies, number of children, history of breastfeeding and pregnancy problems, reason for caesarean section. Section 2: Infants' information including weight, sex, first and fifth minute Apgar. Section 3: Evaluation form of infant feeding behavior consisting of the evaluation of standard Infant Breastfeeding Assessment Tool (IBFAT).
This tool is used for quick assessment of the adequacy of breastfeeding and represents the four main components of breastfeeding: (1) readiness to feed, (2) rooting, (3) latching, and (4) sucking. Scores for each of the four components range from 0 to 3 . The total score can range from 0 to 12 , with 12 representing strong and effective lactation. ${ }^{20}$ In one study by Beiranvand et al, ${ }^{21}$ the validity and reliability of this standard form were calculated and used. The data were recorded in the first hour of birth and the first feeding of the infant and then recorded at $6,12,24,36$ and 48 hours. In order not to interfere with the infants' sleep in the designated hours, the information was considered acceptable one and a half hours before or after it. Data related to this section were recorded by a research assistant (a female nurse). Section 4: A questionnaire about the number and frequency of infants' breastfeeding including parental diary of infant behavior. This form was completed simultaneously with infants' feeding by the mother. This is a standard international instrument consisting of four rulers which are graded 
at each of the 6 hours of the day with a precision of five minutes. Parents were asked to indicate the number and length of breastfeeding on this ruler. During this period, the researcher called the mothers by telephone daily to remind them to complete the form. This questionnaire has been used in a similar article. ${ }^{22}$

In this study, the required permissions were obtained from the authorities and the Research School of Nursing, hospital officials in charge of the operating room of Gerash Amiralmomenin hospital and ethical issues were considered. Then, the pregnant women undergoing cesarean section who were eligible to enter the study were selected after signing the informed consent form. Demographic information was obtained through the information recorded in the document and parents' interviews. First, the standard breastfeeding method was taught by a researcher (female nurse) to all mothers who were eligible to enter the study. $10 \mathrm{~mL} / \mathrm{kg}$ Ringer serum was administrated with the arrival of the pregnant mother in the operating room and 15 minutes before spinal anesthesia. Then, an anesthesiologist, who was also a research associate, performed spinal anesthesia. After the birth of the infant and clamping of the umbilical cord, the baby was dried and put in the blanket; then, the 1st and 5th minute Apgar scores were estimated and recorded by the researcher. For the control group, routine care (100 $\mathrm{mg}$ diclofenac suppository) was provided while in the intervention group, a single dose of $100 \mathrm{mg}$ pethidine was injected intravenously by the anesthesiologist. After the end of the operation, the mother was under care until removing of the sensory-motor block in the recovery room and then sent to the hospital ward. For both groups, skin contact was performed on the skin of the mother and the infant. To maintain the temperature of the infants, we covered the babies with suitable hats and covers on their back. At the time of the mother's admission to the hospital, no other intravenous or oral drugs were given to the test and control group mothers. In case of pain and the mother's need for painkillers, analgesics were prescribed and the mother was excluded from the study. Within 48 hours of hospitalization, the feeding behaviors of both groups were recorded by the researcher and her assistant. On discharge, a DVD containing maternal care of the infant was given to the control and test group subjects as a gift. It should be noted that the temperature of the operation room, recovery room and hospital ward was recorded during the study period. These two variables were the same in both groups. Moreover, anesthesia was performed in both the test and control groups by the same anesthesiologist (the research assistant). During the study, the surgeon, the recovery technician, and the nurses were not informed about the patients' assignment.

\section{Data Analysis}

Descriptive statistics, chi-square, and independent t-test were used on the SPSS 22 software. The information was used for data analysis. The significance level was 0.05 .
Results

Based on independent $t$ test, variables such as maternal age and weight, gestational age, birth weight and first and fifth-minute Apgar scores were compared between the control and test groups. There was no statistically significant difference between the two groups in terms of maternal age $(P=0.148)$, maternal weight $(P=0.189)$, gestational age $(P=0.623)$, birth weight $(P=0.167)$, first minute Apgar score $(P=0.125)$, and fifth minute Apgar score $(P=0.473)$; according to the Chi-square test, the two groups were homogeneous with respect to parity, educational level, previous breastfeeding experience and Apgar score $(P>0.05)$ (Table 1$)$.

According to the independent $t$ test, the highest score of feeding behavior in the control group was related to sucking reflex, and the lowest score in the pethidine group was related to readiness for feeding. According to the results, readiness for feeding in the control group $(2.09 \pm 0.53)$ was significantly higher $(P=0.015)$ than the pethidine group ( $1.81 \pm 0.61)$; also, the sucking reflex score was $2.51 \pm 0.43$ in the pethidine group and $2.54 \pm 0.49$ in the control group, but the difference was not statistically significant $(P=0.687)$, sticking to the mother's chest was not statistically significant $(P=0.118)$ between the pethidine group $(2.65 \pm 0.45)$ and the control group $(2.52 \pm 0.38)$, and rooting reflexes $(P=0.747)$ were almost equal in the pethidine group $(2.46 \pm 0.53)$ and control group $(2.5 \pm 0.48)$. The total score of feeding behavior in the control group $(9.66 \pm 1.04)$ was higher than that of the pethidine group ( $9.44 \pm 1.08)$, although this difference was not statistically significant $(P=0.306)$ (Table 2$)$.

The infants' mean score of feeding in the first hour of birth in the control group $(8.37 \pm 1.41)$ was lower than that of the pethidine group $(8.37 \pm 1.41)$, but it was not statistically significant $(P=0.763)$. At the sixth $(P=0.010)$ and twelfth $(P<0.001)$ hours, the mean score of feeding behavior in the pethidine group $(9.16 \pm 1.06$ and $9.29 \pm 1.25$, respectively) was significantly lower than the control group $(8.40 \pm 1.74$ and $8.37 \pm 1.25$, respectively). After 24 hours, the feeding behavior score of the control group $(9.98 \pm 1.10)$ was higher than the pethidine group $(9.88 \pm 1.65)$, although this difference was not significant $(P=0.734)$. At 36 and 48 hours after birth, the mean score of feeding behavior in the pethidine group $(10.71 \pm 1.24$ and $10.83 \pm 1.11$, respectively) was slightly more than the control group ( $10.59 \pm 1.06$ and $10.61 \pm 1.44$, respectively). The difference was not statistically significant between the two groups ( $\mathrm{P}=0.593$ and 0.403 , respectively) (Table 3 ).

According to independent t-test, the mean score of infants feeding frequency was $8.14 \pm 3.06$ in the control group and $7.31 \pm 2.15$ in the pethidine group $(P=0.137)$. Moreover, the duration of feeding was $11.67 \pm 3.94$ minutes in the control group and $13.05 \pm 4.70$ minutes in the pethidine group $(P=0.140)$. The two groups did not have a significant difference in the number of feeding and duration of feeding (Table 4). 
Table 1. Demographics and Characteristics of the Study Participants (Mothers and Infants)

\begin{tabular}{|c|c|c|c|}
\hline Characteristics & Pethidine Group & Routine Care & $P$ Value \\
\hline \multicolumn{4}{|l|}{ Mothers } \\
\hline Mother's age (years) & 27.73 (SD 5.09) & $29.14(\mathrm{SD} 4.60)$ & $0.148^{*}$ \\
\hline Mother's weight (kg) & $73.46(\mathrm{SD} 8.11)$ & $71.18(\mathrm{SD} 9.16)$ & $0.189 *$ \\
\hline Parity & & & $0.139^{* *}$ \\
\hline Nulliparous & $31(59.6 \%)$ & $22(45 \%)$ & \\
\hline Prima- or multiparous & $21(40.4 \%)$ & $27(55 \%)$ & \\
\hline Educational level & & & $0.595^{* *}$ \\
\hline Primary school graduate & $5(9.6 \%)$ & $1(2 \%)$ & \\
\hline Secondary school graduation & $14(27 \%)$ & $19(39 \%)$ & \\
\hline High school graduation & $29(55 / 7 \%)$ & $23(47 \%)$ & \\
\hline University graduation & $4(7.7 \%)$ & $6(12 \%)$ & \\
\hline Previous breastfeeding experience & & & $0.206^{* *}$ \\
\hline Yes & $19(36.5 \%)$ & $24(49 \%)$ & \\
\hline No & $33(63.5 \%)$ & $25(51 \%)$ & \\
\hline \multicolumn{4}{|l|}{ Newborns } \\
\hline Birth weight (g) & 3517 (SD 400) & 3418 (SD 303) & $0.167^{*}$ \\
\hline \multicolumn{4}{|l|}{ Gender } \\
\hline Girls & $25(48 \%)$ & $23(47 \%)$ & $0.909^{* *}$ \\
\hline Boys & $27(52 \%)$ & $26(53 \%)$ & \\
\hline Gestational age (wk) & 39.52 (SD .94) & 39.62 (SD 1.0) & $0.623^{*}$ \\
\hline \multicolumn{4}{|l|}{ Apgar score } \\
\hline At 1 minute & $8.62(\mathrm{SD} .77)$ & $8.39(\mathrm{SD} .70)$ & $0.125^{*}$ \\
\hline At 5 minutes & $8.94(\mathrm{SD} .72)$ & $9.04(\mathrm{SD} .64)$ & $0.473^{*}$ \\
\hline
\end{tabular}

Data are mean $(\mathrm{SD})$ or number $(\%)$ values. * Independent $t$ test; ${ }^{* *}$ Chi-square test.

Table 2. Breastfeeding Assessment of the Infants in the Pethidine and Routine Care Groups

\begin{tabular}{|c|c|c|c|c|c|c|}
\hline \multirow{2}{*}{ Variable } & \multicolumn{2}{|c|}{ Group } & \multirow{2}{*}{ Mean Difference } & \multicolumn{2}{|c|}{$95 \%$ Confidence Interval } & \multirow{2}{*}{$P$ Value ${ }^{*}$} \\
\hline & Pethidine & Routine Care & & Lower Bound & Upper Bound & \\
\hline Readiness to feed & $1.81 \pm 0.61$ & $2.09 \pm 0.53$ & 0.2822 & 0.0552 & 0.5092 & 0.015 \\
\hline Fixing (latch on) & $2.65 \pm 0.45$ & $2.52 \pm 0.38$ & -0.1333 & -0.3012 & 0.0345 & 0.118 \\
\hline Sucking reflex & $2.51 \pm 0.43$ & $2.54 \pm 0.49$ & 0.0373 & -0.1461 & 0.2208 & 0.687 \\
\hline Rooting & $2.46 \pm 0.53$ & $2.5 \pm 0.48$ & 0.0328 & -0.1685 & 0.2342 & 0.747 \\
\hline IBFAT total mean score & $9.44 \pm 1.08$ & $9.66 \pm 1.04$ & 0.2190 & -0.2032 & 0.6412 & 0.306 \\
\hline
\end{tabular}

* Independent $t$ test.

\section{Discussion}

In previous studies, the potential effects of pethidine use during childbirth under epidural anesthesia or during normal labor have been investigated, and the neonatal evaluation has been limited to Neuro-Behavioral Score or Apgar score. These tools do not reflect the complex behaviors in the breast-feeding of infants. In the present study, a valid tool specific to the assessment of infant feeding behavior was used.

Our study showed that in evaluation of infants in the first 48 hours of birth for readiness to be fed, infants whose mothers received pethidine were less willing to start breastfeeding $(P=0.015)$. In assessment of other components of feeding behavior of the infant (sucking, rooting reflex, latching), there was no significant difference between the two groups. Also, the total score of feeding behavior was similar in both groups. In our study, the mean score of the number of feeding after 48 hours in the pethidine group was slightly more than the control group $(P=0.064)$.

Wiener et $\mathrm{al}^{23}$ compared 18 mothers who received 100 to $300 \mathrm{mg}$ of pethidine during labor with 11 mothers who received epidural anesthesia. They measured the sucking frequency of the infant breast-feeding, the sucking pressure, and the amount of milk used by the infant in 6 times up to 48 hours after the birth. There was no significant difference in the feeding behavior between the two groups, except that 12 hours after birth, the number of sucking babies in the two groups showed a statistically significant difference $(P=0.01)$. In a study by Nissen et $\mathrm{al}^{18} 100 \mathrm{mg}$ pethidine was given to 13 selected mothers 
Table 3. Infant Breastfeeding Assessment Tool (IBFAT) Scores of Newborns After birth $(\mathrm{N}=101)$

\begin{tabular}{|c|c|c|c|c|c|c|}
\hline \multirow{2}{*}{ Time (h) } & \multicolumn{2}{|c|}{ Group } & \multirow{2}{*}{ Mean Difference } & \multicolumn{2}{|c|}{$95 \%$ Confidence Interval } & \multirow{2}{*}{$P$ Value $^{*}$} \\
\hline & Pethidine & Routine Care & & Lower Bound & Upper Bound & \\
\hline 1 & $8.46 \pm 1.69$ & $8.37 \pm 1.41$ & -0.094 & -0.712 & .524 & 0.763 \\
\hline 6 & $8.40 \pm 1.74$ & $9.16 \pm 1.06$ & 0.759 & 0.185 & 1.334 & 0.010 \\
\hline 12 & $8.37 \pm 1.25$ & $9.29 \pm 1.25$ & 0.920 & 0.424 & 1.416 & $<0.001$ \\
\hline 24 & $9.88 \pm 1.65$ & $9.98 \pm 1.10$ & 0.095 & -0.464 & 0.654 & 0.734 \\
\hline 36 & $10.71 \pm 1.24$ & $10.59 \pm 1.06$ & -0.124 & -0.581 & 0.334 & 0.593 \\
\hline 48 & $10.83 \pm 1.11$ & $10.61 \pm 1.44$ & -0.215 & -0.722 & 0.292 & 0.403 \\
\hline IBFAT total mean score & $9.44 \pm .69$ & $9.66 \pm .49$ & 0.22368 & -.01511 & 0.46247 & 0.064 \\
\hline
\end{tabular}

* Independent t-test

Table 4. Comparison of the Mean Frequency and Duration of Feeding Newborns in the Two Groups (48 h)

\begin{tabular}{|c|c|c|c|c|c|c|}
\hline \multirow{2}{*}{ Variable } & \multicolumn{2}{|c|}{ Group } & \multirow{2}{*}{ Mean Difference } & \multicolumn{2}{|c|}{ 95\% Confidence Interval } & \multirow{2}{*}{$P$ Value } \\
\hline & Pethidine & Routine Care & & Lower Bound & Upper Bound & \\
\hline Breast-Feeding Frequency (feeds per day) & $7.31 \pm 2.15$ & $8.14 \pm 3.06$ & 0.830 & -0.269 & 1.930 & 0.137 \\
\hline Breast-Feeding duration (min) & $13.05 \pm 4.70$ & $11.67 \pm 3.94$ & -1.3735 & -3.2067 & 0.4597 & 0.140 \\
\hline
\end{tabular}

* Independent $t$ test.

undergoing vaginal delivery during labor. He reported that the use of pethidine, as a pain reliever during delivery, might have an adverse effect on the breastfeeding behavior of the infant if the interval between medication and infant's birth is short. In two studies, Hadgkinson ${ }^{24,25}$ showed that pethidine significantly reduced the rooting reflexes in infants at 2,4 and 24 hours $(P=0.02,05.02$ and 02.02 , respectively) and on the first and second days after birth $(P=0.001)$. In the second study, it was reported that only $26 \%$ of the infants whose mothers received pethidine during delivery had a high score in the mother's breast rooting reflex.

Bai et $a l,{ }^{26}$ in a cohort study on mothers who received pethidine during labor and after 2, 3, 6 and 9 months of delivery, with the control of confounding factors such as maternal age, number of children and income, came to the conclusion that administration of pethidine during labor increases the risk of stopping infants breastfeeding nor reduces exclusive breastfeeding. In that study, they did not differentiate between the infants exposed to pethidine through breast milk or through the mother's placenta. However, although pethidine alone did not affect the behavior of breast-feeding, women with multiple interventions (caesarean section, epidural anesthesia, injection of pethidine) were at risk of reduced length of the lactation period $(P=0.001)$

By reviewing different studies, it can be concluded that the administration route and the dose of pethidine in different studies have led to different results. The amount of pethidine received by infants through breastfeeding is low, ${ }^{27,28}$ and it seems that nothing threatens the infants after a single dose of pethidine in breastfeeding behavior. In our study, pethidine caused the infants whose mothers received pethidine after caesarean section to be less ready to start breast-feeding; in this case, the mother should be followed and more supported. Breast feeding behavioral score in the pethidine and control groups was the same and the newborns showed acceptable feeding behavior in both groups.

The limitations of this study are as follows: (1) Neonates were asleep during the visit to the hospital ward which led to the need for multiple referral to the ward to complete the data registration; (2) Due to the discharge of mothers after surgery, which sometimes lasted less than 48 hours, there was no more time to study the variables; (3) Results related to the frequency and duration of infant breastfeeding were generally based on mother's memories not recorded documents by an independent observer; and (4) Poor collaboration of some nursing and medical staff in conducting the research project, although by giving necessary explanations, we made an attempt to encourage their contribution.

In conclusion, in the assessment of infants in the first 48

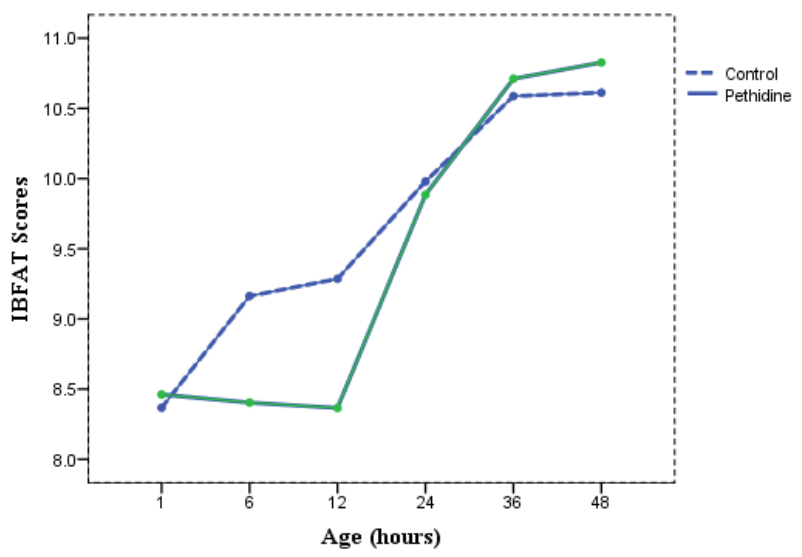

Figure 2. Comparison of the Mean Feeding Behavior of Newborns in the Control and pethidine Groups. 
hours of birth, readiness for breastfeeding was determined. Infants whose mothers received pethidine were less ready to start breastfeeding, but other components of breastfeeding behaviors of the infants were similar (sucking, latching and rooting behaviors) in both groups. Moreover, there was no significant difference between the total score of feeding behavior and infants' feeding frequency and duration of feeding in the control and test groups.

\section{Authors' Contributions}

MD and MA prepared the first draft of the manuscript and MA and made critical revisions to the paper and responded the reviewers and critically reviewed manuscript.ZM collaborated in Proposal approval process, conceptualized and designed the study and Surge Articles and Clinical Research.JS and MR conceptualized and designed the study, edited and critically reviewed manuscript; All authors reviewed and approved the final draft of manuscript.

\section{Conflict of Interest Disclosures}

The authors declare that they have no conflict of interest.

\section{Ethical Statement}

This is an interventional study of clinical trial type that was confirmed by Ethics Committee of Shiraz University of Medical Sciences (IR.SUMS.REC.1396.65) registered at the clinical trial center with the code number IRCT2017042233163N2. All samples had a written consent form and if they did not wish to continue to participate in the research project, they could withdraw from the study.

\section{Acknowledgments}

The authors would like to thank Shiraz University of Medical Sciences, Shiraz, Iran and also the Center for Development of Clinical Research of Nemazee Hospital and Dr. Nasrin Shokrpour for editorial assistance.

\section{References}

1. Jouhari S, Bayati S, Poor Asadi Kheirabadi F, Moradi E. Cesarean section rate and its cause in Fasa in the year 2011. J Fasa Univ Med Sci. 2014;4(3):295-300. [Persian].

2. Moore B. Appropriate technology for birth. Lancet. 1985;326(8458):787. doi: 10.1016/s0140-6736(85)90673-7.

3. Adekanle DA, Adeyemi AS, Fasanu AO. Caesarean section at a tertiary institution in Southwestern Nigeria-a 6-year audit. Open J Obstet Gynecol. 2013;3(3):357-61. doi: 10.4236/ojog.2013.33066.

4. Al-Mabslai R, Gowri V. Woman-centered care in pregnancy and childbirth. Sultan Qaboos Univ Med J. 2011;11(2):2912.

5. Xie RH, Gaudet L, Krewski D, Graham ID, Walker MC, Wen SW. Higher cesarean delivery rates are associated with higher infant mortality rates in industrialized countries. Birth. 2015;42(1):62-9. doi: 10.1111/birt.12153.

6. Ostovar R, Hossein Rashidi B, Haghallahi F, Fararoei M, Rasouli M, Naeimi E. Non-medical factors on choice of delivery (CS/NVD) in hospitals of Tehran University of Medical Sciences. Open J Obstet Gynecol. 2013;3(1):67-73. doi: 10.4236/ojog.2013.31015.

7. Azimirad A. Cesarean section beyond Cesar's borders: a mini review on the cultural history of cesarean section high prevalence rates in the Middle East. Arch Iran Med. 2020;23(5):335-7. doi: 10.34172/aim.2020.23.

8. Direkvand-Moghadam A, Delpisheh A, Rezaeian M, Khosravi A. Factors affecting the labor: a review article. Biomed Pharmacol J. 2015;6(2):161-7. doi: 10.13005/ bpj/399.

9. Patel N. Anesthesia for cesarean delivery. J Adv Med Dent Sci Res. 2015;3(4):25-9.

10. Foruzeshfard M, Validad E, Mirmohamadkhani M, Moradan S. Type of anesthesia chosen by mothers for cesarean section in their first delivery and its related factors in selected hospitals in year 2012. Iran J Obstet Gynecol Infertil. 2013;15(39):1-8. doi: 10.22038/ijogi.2013.540.

11. Ripollés Melchor J, Espinosa Á, Martínez Hurtado E, Casans Francés R, Navarro Pérez R, Abad Gurumeta $\mathrm{A}$, et al. Colloids versus crystalloids in the prevention of hypotension induced by spinal anesthesia in elective cesarean section. A systematic review and meta-analysis. Minerva Anestesiol. 2015;81(9):1019-30.

12. Cobb B, Liu R, Valentine E, Onuoha O. Breastfeeding after anesthesia: a review for anesthesia providers regarding the transfer of medications into breast milk. Transl Perioper Pain Med. 2015;1(2):1-7.

13. Nooripoor S, Moradan S, Gorbani R, Hemmati AA, Delghandi M. Comparison of the effects of general anesthesia and spinal analgesia on newborns' Apgar score in cesarean section. Iran J Obstet Gynecol Infertil. 2015;17(135):1-8. doi: 10.22038/ijogi.2015.4053.

14. Yousefshahi F, Asadi M, Rahimi F, Hoseinzade MJ, Davari Tanha F, Barkhordari K, et al. The effect of meperidine on peripartum breastfeeding and neonatal weight. J Family Reprod Health. 2013;7(1):29-34.

15. Burchell T, Coster S, Norman I. The effect of intrapartum pethidine on breastfeeding: a scoping review. Evid Based Midwifery. 2016;14(2):49-56.

16. Wang K, Cao L, Deng Q, Sun LQ, Gu TY, Song J, et al. The effects of epidural/spinal opioids in labour analgesia on neonatal outcomes: a meta-analysis of randomized controlled trials. Can J Anaesth. 2014;61(8):695-709. doi: 10.1007/s12630-014-0185-y.

17. Ransjö-Arvidson AB, Matthiesen AS, Lilja G, Nissen E, Widström AM, Uvnäs-Moberg K. Maternal analgesia during labor disturbs newborn behavior: effects on breastfeeding, temperature, and crying. Birth. 2001;28(1):512. doi: 10.1046/j.1523-536x.2001.00005.x.

18. Nissen E, Lilja G, Matthiesen AS, Ransjö-Arvidsson AB, Uvnäs-Moberg K, Widström AM. Effects of maternal pethidine on infants' developing breast feeding behaviour. Acta Paediatr. 1995;84(2):140-5. doi: 10.1111/j.16512227.1995.tb13596.x.

19. Sakalidis VS, Williams TM, Hepworth AR, Garbin CP, Hartmann PE, Paech MJ, et al. A comparison of early sucking dynamics during breastfeeding after cesarean section and vaginal birth. Breastfeed Med. 2013;8(1):79-85. doi: $10.1089 / \mathrm{bfm} .2012 .0018$.

20. Matthews MK. Mothers' satisfaction with their neonates' breastfeeding behaviors. J Obstet Gynecol Neonatal Nurs. 1991;20(1):49-55. doi: 10.1111/j.1552-6909.1991.tb01676.x.

21. Beiranvand S, Valizadeh F, Hosseinabadi R. The effect of skin-to-skin contact of mother and newborns on breastfeeding status in full-term newborns after cesarean 
delivery. Modern Care J. 2014;10(4):288-95. [Persian].

22. Raisi-Dehkordi Z, Delaram M, Hosseini-Baharanchi FS. The effect of infant massage on the frequency and duration of breast feeding- a randomized clinical trial. J Clin Nurs Midwifery. 2013;2(3):19-27. [Persian].

23. Wiener PC, Hogg MI, Rosen M. Neonatal respiration, feeding and neurobehavioural state. Effects of intrapartum bupivacaine, pethidine and pethidine reversed by naloxone. Anaesthesia. 1979;34(10):996-1004. doi: 10.1111/j.13652044.1979.tb06247.x.

24. Hodgkinson R, Bhatt M, Grewal G, Marx GF. Neonatal neurobehavior in the first 48 hours of life: effect of the administration of meperidine with and without naloxone in the mother. Pediatrics. 1978;62(3):294-8. doi: 10.1097/00132586-197912000-00039.

25. Hodgkinson R, Huff RW, Hayashi RH, Husain FJ. Doubleblind comparison of maternal analgesia and neonatal neurobehaviour following intravenous butorphanol and meperidine. J Int Med Res. 1979;7(3):224-30. doi: 10.1177/030006057900700310.

26. Bai DL, Wu KM, Tarrant M. Association between intrapartum interventions and breastfeeding duration. J Midwifery Womens Health. 2013;58(1):25-32. doi: 10.1111/j.1542-2011.2012.00254.x.

27. Al-Tamimi Y, Ilett KF, Paech MJ, O'Halloran SJ, Hartmann PE. Estimation of infant dose and exposure to pethidine and norpethidine via breast milk following patient-controlled epidural pethidine for analgesia post caesarean delivery. Int J Obstet Anesth. 2011;20(2):128-34. doi: 10.1016/j. ijoa.2010.12.004.

28. Peiker G, Müller B, Ihn W, Nöschel H. [Excretion of pethidine in mother's milk (author's transl)]. Zentralbl Gynakol. 1980;102(10):537-41. 